\title{
Research on Precision Marketing Model under the Internet and Big Data Background
}

\author{
Yuanning Shi \\ Qinghai University of Finance and Economics College, QingHai, XiNing, 810016, China
}

Keywords: Precision Marketing, Model, Big Data, Internet, Background, Literature Analysis.

\begin{abstract}
This paper introduces the research on precision marketing model under the Internet and big data background. With the popularity of network shopping is more and more high, the personalized needs of customers or consumers more and more apparent. Personalized demand is based on accurate market positioning, on the basis of market positioning further to different customers or consumers to provide the required services. Modern consumers are no longer a simple sense of material, but the consumption of the whole and complete perceptual consumers and manufacturers product through the "perceptual value" to create the differentiated competitive advantage. Our research combines latest research result to propose our new idea that will be meaningful.
\end{abstract}

\section{Introduction}

Philip Kotler put forward the "precision marketing" in recent years. He thinks, the enterprise needs to be more precise, measurable and high return on investment of marketing communication and need to pay more attention to the results and action plan to marketing communications, there are more and more attention to investment in direct marketing communication.

In daily life, precision marketing has been more and more taken seriously enterprises have to carry favor this way of the marketing. Facts have proved that the precision marketing has a very attractive advantages and characteristics. Because accurate marketing on the basis of accurate positioning, rely on the database and the general modern information technology, build a more personalized customer communication and the service system, make up for the deficiency of the traditional marketing model, accurately grasp the differentiation of the target market demand, rapid capture appetite of consumers, thus got the favor of a large number of enterprises.

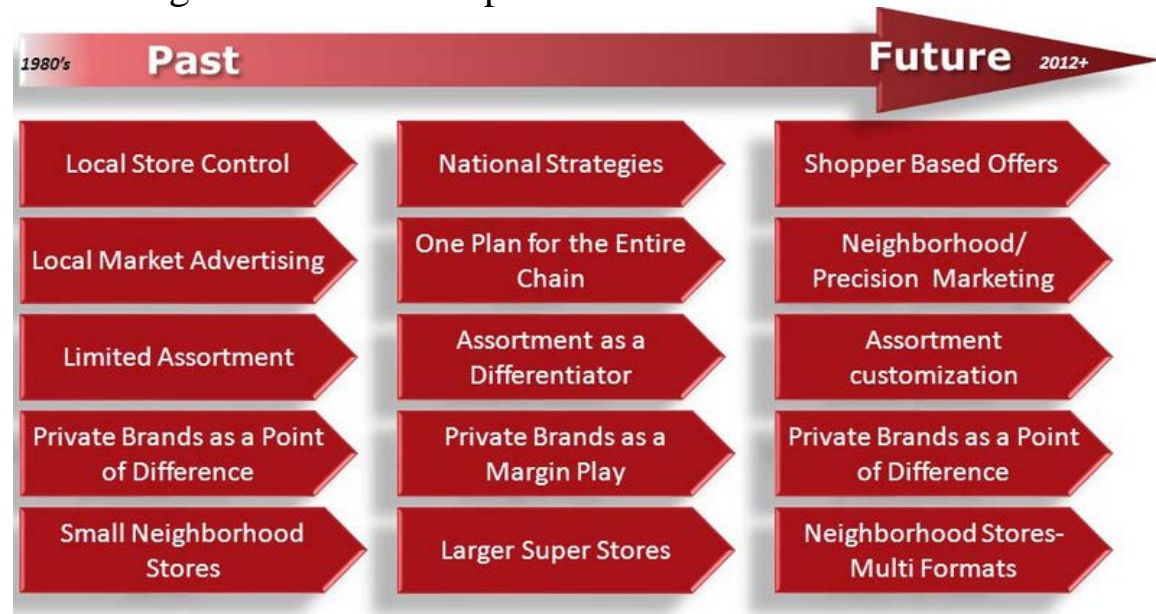

Fig. 1 The Developmental Trend of the Marketing Model

In the figure one, we show the developmental trend of the marketing model. Based on this basic architecture, we could summarize the systematic description of the marketing from the listed aspects. (1) The monopoly condition, the companies give their products a clear, unique market positioning as is to carry out the necessary foundation of the precision marketing. (2) Enterprises to implement the accurate marketing, first of all, on the basis of market segmentation to choose specific segments as the target market of enterprise and to clearly describe the target consumers demand characteristics of the product. (3) Customers value-added service system through the related services to further enhance the 
cognitive value of customers to buy later, to increase customer lifetime value by increasing customer loyalty, achieve win-win customers and enterprises. This is the long-term goal of precision marketing.

\section{Our Proposed Methodology and Perspective}

\subsection{Big Data and Marketing.}

Big data contains structured and basic unstructured and semi-structured data types, especially in a structured and semi-structured data is given priority to, so different general database, the processing is very complicated. So for the use of big data cannot only focus on big data itself, but also from the data analysis, data mining, such as angle to think can extract real data used in this enterprise is valuable. Big data marketing has significant difference with traditional marketing model, from classification of large data marketing can be divided into the two types has its own class and the third party platform.

- Their own kind of big data marketing. This type of marketing is based on their own network platform development and mining of the data.

- The third party platform. The so-called third party platform is enterprise with the web portal, search engine, e-commerce sites, and a third party, such as mobile payment platform, platform for cooperation to obtain the required data.

- Mass user resources because of the big data to marketing for big data accuracy could promote, more help to achieve precise marketing data.

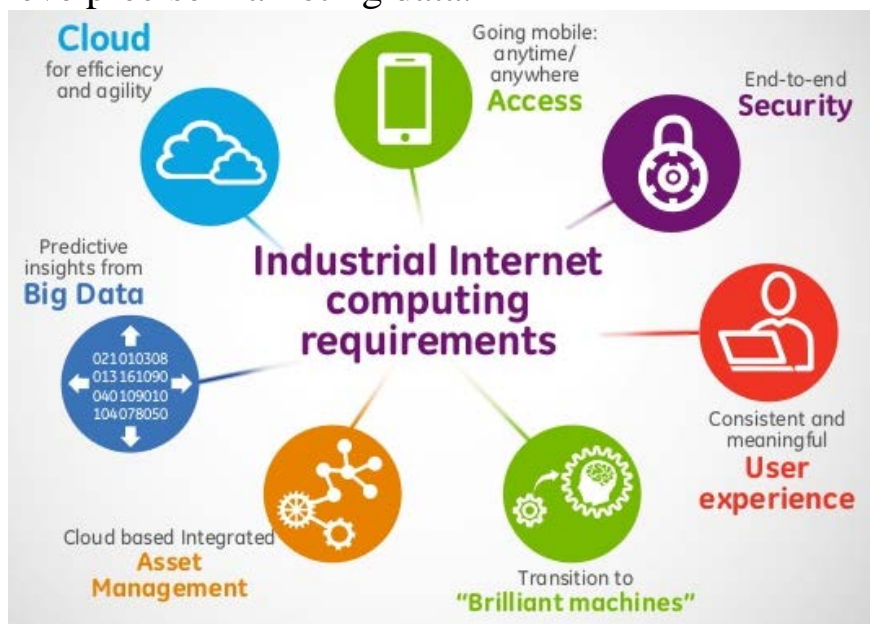

Fig. 2 The Big Data Architecture and the Corresponding Applications

\subsection{Marketing Roles.}

American marketing expert Philip Kotler put development of consumer demand roughly divided into three stages: the first is the amount of consumption as the second is the qualitative consumption age and the third is the perceptual consumption age. Conform to the market law of development, from product economy to the service economy, to experience economy of today. The advent of the era of the perceptual consumption is no accident that has its profound background.

Modern consumers are no longer a simple sense of material, but the consumption of the whole and complete perceptual consumers and manufacturers product through the "perceptual value" to create the differentiated competitive advantage. The public doesn't know what can, but we know. Customers so we don't have a lot of market research, but to complete her about the concept of the product, and through the education of the public, to communicate with the public to try to create a market for the products. So that consumer can be induced that demand can be created.

Manufacturers, therefore, as long as fully excavate potential, people are not aware of or have realized but pay attention to the perceptual demand of enough field, and put it into the market in time, even in a saturated market can still fission new markets, to bring unlimited business opportunities. In perceptual consumption age, besides the function of the product value, consumers pay attention to the emotional value, product especially externalization and the feeling of visible as is the most powerful impact customers' market behavior. So in general perceptual consumption age, packaging design is undoubtedly show charm products and won the consumers and a winning strategy. 


\subsection{The Internet Marketing.}

Internet marketing is the use of the digital information and network media interaction to assist marketing goals of a new way of marketing. As social media, the media, the emergence and popularity of network information communication tools such as advertising and content marketing has become marketing trend, and has been widely used in practice. At present, through a variety of basic media, including print, video, audio, etc., to transfer information and enterprise target consumer groups, and through this way to attract the target consumer groups of the enterprise, notice the enterprise brand awareness, so that they produce and the general formation of corporate brand identity, improve their recognition, as encouraging them to eventually purchase or repeated the purchase decision marketing methods are referred to as content marketing.

Network marketing tool interactive degree is different and there is a direct interaction and indirect interaction interactive network marketing tools, and that core synchronous and asynchronous network marketing tools can be organized as the follows.

- With the industry web site, supply chain upstream and downstream enterprises of the link can further expanding the scope of the dissemination of information. Industry web site itself with platform effect.

- In the search engine log in and get a good ranking is one of basic tasks of website promotion. Search engine log on only the primary form of search engine marketing, keyword advertising, to search engine marketing positioning is more one step further, because the use of keywords retrieval way, in the search results page displays the contents of advertisements, it can realize the advanced positioning.

- Have the basic information of consumers, the need for information storage and analysis, this is about to use online database to store consumers information in time, using the data mining tool to analysis the demand of consumer preferences, group of consumers preferences similar can be divided into a group, in order to have a purpose to send information.

\subsection{Precision Marketing Model.}

Alleged market segmentation, it is according to the different consumer demand and resources, geographical location, buying habits and other aspects of the difference of the classification, form a "niche". In the process of marketing, it is only through market segmentation and enterprise can better choose target market, a targeted marketing strategy planning, design and development of the new products, develop appropriate commodity prices, choose the optimal sales channels and promotion methods, explore and occupy the target market.

Advertisers all policy is to have market effect. Are constantly stressed accurately targeted, is also in order to enhance communication effect. The effect of another driver is that the innovation strategy. Traditional advertising form at present already cannot satisfy the advertisers and the market demand. We advocate the precision marketing, more specifically, should be accurate marketing innovation.

- After determine the target market, but also should be accurate product positioning, in the fierce market competition environment, each target market has a large number of competitors, only to a unique product, clear, creative positioning, on product features, image, marketing, design should be targeted to stand out from competition, harvest the target market.

- A major feature of precision marketing is emphasis on the effectiveness of communication strategy. In the process of enterprise executive precision marketing, build good customer communication become enterprises is an important content of precision marketing, and make the enterprise at a reasonable cost of the marketing brings good marketing effect. Usually enterprise and customer contacts occur during the process of enterprise marketing.

- In response to the strong development of new media, traditional media is in itself for further cooperation. From the form of primary intermediate cooperation, cooperation, integration of content to the concept of combination of advanced cooperation, traditional media channels through interaction, the original secondary or even several times the development and basic utilization of resources, and form multiple terminal touch audience of advantage, through the form and content, for advertisers to provide more convenience and opportunities. 
It is the development of the enterprise products and the services to the target market and the target customers with unique interests and core values of process is also an important link of the enterprise marketing innovation of customer involvement, and customer involvement in product development objective management put forward the higher request, about the content, the form of the customer involvement with enterprise inherent in the product development process integration, and on the basis of the guarantee of the management cost of implementing customer involvement, and in the process, improve customer for the product cognition and value judgment standard, eventually the enterprise products and services to meet the industry standard development cycle are listed.

\subsection{The Future of the Marketing Activities.}

Establish marketing theory of marketing knowledge. Knowledge marketing is not to inculcate a concept to consumer, a kind of technology, products category, but with the demands of consumers and potential demand, offer relevant products and related knowledge, information, in the dissemination of knowledge to achieve the interaction between unique customers, thus subtly tell consumers valuable information, to help consumers in the complicated product shelves choose the most suitable products, promote the rational consumption, thus helping the enterprises customers, expanding market demand.

Based on the prior discussion, we propose the suggestions to the related issues. (1) Consumer alliance that based on the consumer to join and enterprise alliance, in return for the interests of the consumers driving mechanism of a new type of marketing. (2) Big marketing. Marketing is the traditional marketing mix strategy of continuous development. The theory put forward by the United States Philip Kotler marketing home that he points out that the enterprise in order to enter a specific market, where he engaged in business management, on the strategy should be coordinated to use economic, psychological, political, public relations, and to impress the foreign or local all aspects of the cooperation and the support, so as to achieve the desired purpose. (3) Personalized marketing. The enterprise release the attention to person, a person's personality and personality to meet demand on an unprecedented center position, enterprise and the market gradually establish a new type of the basic relationship, establish the database and information files, as individual consumers establish a more intimate contact with consumers.

\section{Summary and Conclusion}

This paper introduces the research on precision marketing model under the Internet and big data background. Precision marketing this concept was first put forward by world-class marketing master Philip Kotler, he points out that precision marketing is the company that need to be more precise, measurable and high return on investment of marketing communication, need to pay more attention to the results and marketing communication plan of action, and there are more and more attention to investment in direct sales. There is no doubt that the birth of precision marketing theory is due to changes in the environment. But the specific factor of the birth of the precision marketing theory is multifaceted. In the future, we will conduct more research to enhance the current result.

\section{References}

[1]. You, Zhen, et al. "A decision-making framework for precision marketing." Expert Systems with Applications 42.7 (2015): 3357-3367.

[2]. Yuling, Z. E. N. G. "The Accurate Marketing System Design Based on Data Mining Technology: A New Approach." (2015).

[3]. Ozyirmidokuz, Esra Kahya, Kumru Uyar, and Mustafa Hakan Ozyirmidokuz. "A Data Mining Based Approach to a Firm's Marketing Channel." Procedia Economics and Finance 27 (2015).

[4]. Nazari, Maryam, et al. "The Impact of Individual Characteristics on the Creation of Marketing Intelligence." Jurnal UMP Social Sciences and Technology Management Vol 3.3 (2015). 